\title{
Cultivo de morangueiro sob diferentes tipos de mulching
}

\author{
Jony E Yuri'; Geraldo M de Resende ${ }^{1}$; Nivaldo D Costa ${ }^{1}$; José H Mota ${ }^{2}$ \\ 'Embrapa Semiárido, C. Postal 23, 56302-970 Petrolina-PE; jony.yuri@cpatsa.embrapa.br; gmilanez@cpatsa.embrapa.br; ndcosta@ \\ cpatsa.embrapa.br; ${ }^{2}$ UFG, C. Postal 3, 75801-615 Jataí-GO; hortenciomota@terra.com.br
}

\section{RESUMO}

O experimento foi realizado durante os meses de junho a outubro de 2008, no município de Três Corações (MG), à altitude de 864 m. O delineamento experimental utilizado foi de blocos casualizados, em esquema fatorial $2 \times 3$, com três repetições, onde o primeiro fator correspondeu a duas épocas de instalação do mulching, ou seja, antes e depois do transplantio e o segundo, à cor da face externa do filme plástico (preto, branco e prata). As mudas de morango, cultivar Oso Grande, foram transplantadas em 06/06/08. Após 75 dias do transplantio foi iniciada a colheita, que se estendeu até meados de outubro. Avaliaram-se as características número médio de frutos por planta, comprimento médio de fruto $(\mathrm{cm})$, massa fresca de frutos $(\mathrm{g}$ planta $\left.^{-1}\right)$, número médio de folhas por planta e comprimento médio de folíolo $(\mathrm{cm})$. O número médio de frutos e a massa média de frutos apresentaram efeito significativo na interação entre os dois fatores. As características comprimento médio de frutos e número médio de folhas por planta apresentaram efeito significativo de modo isolado, somente para o fator cor de mulching. Assim, nas condições em que foi conduzido o experimento, concluiu-se que os filmes plásticos preto e prata possibilitam aumento no rendimento e maior desenvolvimento de frutos, desde que instalados em pré-transplantio das mudas de morangueiro.

Palavras-chave: Fragaria $x$ ananassa, plasticultura, manejo.

\begin{abstract}
Strawberry cultivation with mulch of different colors and installation times on the beds

The experiment was carried out from June to October 2008 in Três Corações, Minas Gerais state, Brazil. It was in a completely randomized design, in factorial scheme $2 \times 3$ with three replications. The first factor corresponded to two installation times of the mulching (before and after transplanting) and the second was related to three mulching colors (black, silver and white). The strawberry seedlings (cv. Oso Grande) were transplanted on June 6, 2008. The harvest began 75 days after transplanting date, being extended until mid October. Average number of fruits per plant, fruits average length $(\mathrm{cm})$, average fruits fresh mass $\left(\mathrm{g} \mathrm{plant}^{-1}\right)$, average number of leaves per plant and average leaflet length $(\mathrm{cm})$ were evaluated. The average number of fruits and fresh mass showed significant effect in the interaction between the two factors. Average fruit length and number of leaves presented significant effect only for the mulch factor. Thus, in the condition that the experiment was carried out, we can conclude that the black and the silver mulches enabled a yield increase and better fruits development, since it was installed before seedling transplanting.
\end{abstract}

Keywords: Fragaria $x$ ananassa, plasticulture, management.

\section{(Recebido para publicação em 27 de dezembro de 2011; aceito em 9 de julho de 2012) (Received on December 27, 2011; accepted on July 9, 2012)}

$\mathrm{N}^{\circ}$ estado de Minas Gerais, o morangueiro (Fragaria x ananassa) é produzido na maioria dos municípios do extremo Sul, na região da Mantiqueira, sendo Pouso Alegre e Estiva os maiores produtores, e nos Campos das Vertentes, em Barbacena e municípios vizinhos (Filgueira, 2005). O estado responde por $95 \%$ de toda produção nacional, o que corresponde a uma produção anual de aproximadamente 85 mil toneladas (Scicco, 2010). Dentre os principais fatores que proporcionaram destaque ao sul de Minas Gerais, estão as condições climáticas favoráveis para o cultivo e, também, a localização estratégica, próxima aos grandes centros consumidores (Veiga Junior, 2006).

No processo de produção, os tratos culturais são fatores de grande relevância para o êxito da cultura. Nesse contexto, a utilização de cobertura de solo vem se destacando, principalmente, depois do surgimento dos filmes plásticos, que têm encontrado aceitação cada vez maior, devido à sua praticidade de aplicação e, sobretudo, pelas evidentes vantagens que trazem aos cultivos (Sganzerla, 1995).

A aplicação de uma cobertura de solo proporciona maior controle das plantas invasoras, menor consumo de água de irrigação, em face da redução no processo de evaporação e, também, facilita a colheita e comercialização, pois o produto colhido é mais limpo e sadio (Negreiros et al., 2005). Entretanto, ao se cobrir o solo, também são modificados parâmetros importantes do microclima, como a temperatura do solo, cujas amplitudes variam com a absortividade e condutividade térmica do material utilizado na cobertura. Além disso, a temperatura do solo influi na evaporação da água ali presente e no crescimento de microrganismos, fatores esses que, diretamente, também influenciam no consumo de água e no crescimento e desenvolvimento da cultura. No tocante ao controle de plantas invasoras, vale destacar os benefícios do uso de cobertura de solo, uma vez que, com esse método, minimiza-se a utilização de herbicidas e, ao mesmo tempo, reduzem-se as perdas de produção, em razão da competição entre a cultura de interesse econômico e as plantas invasoras (Gonçalvez et al., 2005). Além disso, o teor de umidade constante e a temperatura mais elevada dos solos com cobertura plástica favorecem a atividade microbiana e maior mineralização do nitrogênio orgânico, aumentando a disponibilidade deste nutriente para as plantas nas camadas mais superficiais do solo (Sampaio, 1999).

$\mathrm{Na}$ prática, os produtores do sul de Minas utilizam o filme plástico de cor preta (mulching preto), sendo que 
o mesmo tem sido instalado como cobertura de solo 25 a 30 dias após o processo de transplantio (Resende, 2001). Trata-se de um procedimento muito trabalhoso e demorado, uma vez que há a necessidade de cobrir todo o canteiro com o mulching e, em seguida, procurar os pontos em que se encontram as plantas para que se possa, com o auxílio de uma lâmina, executar o corte do plástico e a retirada das mesmas.

Diferentes tipos de plásticos são utilizados para cobertura dos solos, como filmes pretos, branco, cinza, verde, marrom, amarelo e prateado (dupla-face). No caso dos filmes prateados, estes refletem maior parte dos raios solares, transmitindo pouca energia aos solos, constituindo-se num dos materiais sintéticos mais adequados para regiões quentes, como é o caso da região Nordeste do Brasil (Sganzerla, 1995). Dentre as coberturas de canteiro, o plástico preto é o mais utilizado no cultivo do morangueiro pelos produtores (Groppo \& Tessarioli Neto, 1991). Já Kasperbauer (2000) reportou que o uso de mulching vermelho proporciona maior resposta produtiva que o preto, em razão de que essa coloração possibilita fornecer de forma seletiva tanto a luz vermelha como a luz vermelha distante, ambas consideradas, comprimentos de luz de maiores eficiências fotossintéticas. Por outro lado, Locascio et al. (2005), testando os filmes plásticos de cor vermelha e preta na cultura do morangueiro, nas condições do estado da Flórida, nos EUA, chegaram à conclusão de que o rendimento produtivo do morangueiro não foi afetado significativamente pelos tratamentos, ou seja, tanto o mulching vermelho como o preto apresentaram respostas equivalentes. Da mesma forma, em trabalho de avaliação de diferentes cores de mulching em comparação ao solo sem cobertura, Negreiros et al. (2005), com a cultura do melão, nas condições do município de Mossoró (RN), chegaram à conclusão de que, independentemente da cor do filme plástico, o uso de mulching incrementa a produção da cultura.

Diante desse contexto, com o intuito de verificar os efeitos das diferentes colorações de mulching, aplicados em pré-transplantio ou pós-transplantio, na cultura do morangueiro, realizou-se o presente trabalho nas condições do município de Três Corações (MG).

\section{MATERIAL E MÉTODOS}

O experimento foi realizado durante os meses de junho a outubro de 2008 , no município de Três Corações, fazenda Patrimônio (altitude de $864 \mathrm{~m}$ ). O solo foi classificado como LATOSSOLO VERMELHO distroférrico de textura média (Embrapa, 1999). De acordo com os resultados da análise química do solo, efetuou-se a aplicação de $800 \mathrm{~kg} \mathrm{ha}^{-1} \mathrm{de}$ calcário dolomítico na área experimental, 30 dias antes do plantio, de acordo com a recomendação da $5^{\mathrm{a}}$ Aproximação (Ribeiro et al.,1999).

O delineamento experimental utilizado foi de blocos casualizados, em esquema fatorial $2 \times 3$, com três repetições, onde o primeiro fator correspondeu às duas épocas de instalação do mulching, ou seja, antes e depois do transplantio e o segundo, à cor da face externa do filme plástico (preto, branco e prata). A área experimental foi constituída por 3 canteiros, com largura de $1,1 \mathrm{~m}$, espaçados entre si em $0,5 \mathrm{~m}$ e com o comprimento de 9,0 m cada, totalizando 40,5 m². Cada canteiro correspondeu a um bloco, que foi subdividido em seis parcelas de 1,5 $\mathrm{m}$. Em cada parcela foram transplantadas 20 mudas (no arranjo de 4 fileiras e 5 plantas por fileira). De acordo com os tratamentos referentes ao fator época de instalação do mulching, para aqueles anteriores ao transplantio, efetuou-se essa operação no dia anterior. Já naqueles posteriores ao transplantio, a operação de cobertura do solo foi realizada após um período de 25 dias, ou seja, após o vingamento das mudas. Considerou-se como parcela útil, as seis plantas das duas linhas internas (três de cada linha), mantendo-se uma planta de cada extremidade dessas linhas e todas das duas linhas externas como bordadura.

Os canteiros foram confeccionados com uma roto-encanteiradora. A adubação de base do solo constou de $40 \mathrm{~kg}$ ha $^{-1}$ de $\mathrm{N}, 400 \mathrm{~kg} \mathrm{ha}^{-1}$ de $\mathrm{P}_{2} \mathrm{O}_{5}, 150 \mathrm{~kg}$ $\mathrm{ha}^{-1}$ de $\mathrm{K}_{2} \mathrm{O}$ tendo como fonte a ureia, superfosfato simples e cloreto de potássio. Nos canteiros confeccionados, logo após a adubação, foram instaladas duas linhas de tubo gotejador com emissores a cada $20 \mathrm{~cm}$ e apresentando uma vazão de $1,7 \mathrm{~L} \mathrm{~h}^{-1}$.

As mudas da cultivar Oso Grande foram transplantadas em 06/06/20. De acordo com o desenvolvimento e a necessidade da cultura, foram realizados o controle de pragas e doenças, irrigações (gotejamento), capinas (entre os canteiros) e adubações de cobertura via fertirrigação, iniciadas após 10 dias do transplantio e realizadas a cada três dias, durante todo o cultivo .

Após 75 dias do transplantio, em 20/08/08, foi iniciada a colheita, que se estendeu até meados de outubro. As colheitas de frutos foram realizadas a cada três dias, descartando-se os defeituosos. A seleção dos mesmos foi realizada com base nas orientações do Centro de Qualidade em Horticultura da CEAGESP (Alvarenga, 2006). Nessas ocasiões, foram avaliadas as características: número médio de frutos por planta; comprimento médio de fruto $(\mathrm{cm})$ e massa fresca de frutos (g planta $\left.{ }^{-1}\right)$. As características número médio de folhas por planta e comprimento médio de folíolo $(\mathrm{cm})$ foram realizadas no primeiro dia de colheita. Para essa última característica, adotou-se como critério para se mensurar o comprimento, o folíolo central da parte basal completamente desenvolvido e sadio. Os dados foram submetidos à análise de variância, sendo as médias avaliadas pelo teste de Tukey em todas as caracteristicas, utilizando o programa SISVAR 4.0 (Ferreira, 1999).

\section{RESULTADOS E DISCUSSÃO}

De acordo com a análise de variância, a característica número médio de frutos apresentou efeito significativo entre os tratamentos, de modo isolado para os fatores época de instalação e cor de filme plástico, assim como para interação entre os dois fatores. Pela análise do desdobramento de cores de mulching dentro de cada época de instalação, constatou-se que em pré-transplantio, os filmes plásticos de cores preta e prata, proporcionaram desempenho superior, resultando em uma quantidade média de 36,3 e 34,0 frutos planta $^{-1}$, respectivamente, sendo estatisticamente superior ao filme plástico branco, que levou ao 
Tabela 1. Número médio e massa média de frutos de morangueiro por planta em função de diferentes cores de mulching e época de instalação (average number and average fresh mass of fruits per plant depending on mulch color and installation time). Três Corações, UNINCOR, 2008.

\begin{tabular}{|c|c|c|c|}
\hline \multirow{3}{*}{ Época de instalação } & \multicolumn{3}{|c|}{ Cor de mulching } \\
\hline & preto & prata & branco \\
\hline & \multicolumn{3}{|c|}{ Número médio de frutos/planta } \\
\hline Pré-transplantio & $36,3 \mathrm{aA}$ & $34,0 \mathrm{aA}$ & $26,0 \mathrm{aB}$ \\
\hline Pós-transplantio & $32,6 \mathrm{bA}$ & $32,3 \mathrm{bA}$ & $25,0 \mathrm{aB}$ \\
\hline $\mathrm{CV}(\%)$ & 2,17 & & \\
\hline \multirow[t]{2}{*}{ Média } & 31,0 & & \\
\hline & \multicolumn{3}{|c|}{ Massa média de fruto/planta (g) } \\
\hline Pré-transplantio & $545,0 \mathrm{aA}$ & $510,0 \mathrm{aA}$ & $390,0 \mathrm{aB}$ \\
\hline Pós-transplantio & $490,0 \mathrm{bA}$ & $485,0 \mathrm{bA}$ & $371,0 \mathrm{aB}$ \\
\hline $\mathrm{CV}(\%)$ & 2,00 & & \\
\hline Média & 465,3 & & \\
\hline
\end{tabular}

Médias seguidas de mesma letra, minúscula nas colunas e maiúscula nas linhas, não diferem significativamente entre si pelo teste de Tukey a $5 \%$ de probabilidade (means followed by the same lowercase letter in the columns and by the uppercase letter in the rows do not differ according to Tukey's test at 5\%).

Tabela 2. Comprimento médio de frutos de morangueiro $(\mathrm{cm})$, número médio de frutos por planta e comprimento médio do folíolo $(\mathrm{cm})$ em função de diferentes cores de mulching e época de instalação (average fruits length $(\mathrm{cm})$, average fruits number and average leaflet length $(\mathrm{cm})$ depending on mulch color and installation time). Três Corações, UNINCOR, 2008 .

\begin{tabular}{lccc}
\hline Cor & $\begin{array}{c}\text { Comprimento } \\
\text { médio de frutos }\end{array}$ & $\begin{array}{c}\text { Número médio } \\
\text { de frutos }\end{array}$ & $\begin{array}{c}\text { Comprimento } \\
\text { médio de folíolo }\end{array}$ \\
\hline Prata & $3,41 \mathrm{a}$ & $10,33 \mathrm{a}$ & $10,03 \mathrm{a}$ \\
Preto & $3,08 \mathrm{ab}$ & $9,83 \mathrm{ab}$ & $9,83 \mathrm{a}$ \\
Branco & $2,91 \mathrm{~b}$ & $9,00 \mathrm{~b}$ & $9,61 \mathrm{a}$ \\
\hline CV $(\%)$ & 6,92 & 7,89 & 5,32 \\
Média & 3,13 & 9,72 & 9,84 \\
\hline Pré-transplantio & $3,11 \mathrm{a}$ & $9,77 \mathrm{a}$ & $9,74 \mathrm{a}$ \\
Pós-transplantio & $3,16 \mathrm{a}$ & $9,66 \mathrm{a}$ & $9,94 \mathrm{a}$ \\
\hline CV (\%) & 6,92 & 7,89 & 5,32 \\
Média & 3,13 & 9,72 & 9,84 \\
\hline
\end{tabular}

Médias seguidas de mesma letra não diferem significativamente entre si pelo teste de Tukey a 5\% de probabilidade (means followed by the same letter do not differ according to Tukey's test at $5 \%$ ).

menor desempenho, com 26,0 frutos planta $^{-1}$. Em relação à instalação em pós-transplantio, verificou-se, assim como em pré-transplantio, superioridade estatística dos filmes plásticos de coloração preta e prata, com 32,6 e 32,3 frutos planta ${ }^{-1}$, respectivamente. Novamente, o filme plástico branco proporcionou desempenho inferior, com 25,0 frutos planta ${ }^{-1}$ (Tabela 1). No caso do cultivo de melão na região Nordeste, que normalmente apresenta temperatura frutos planta ${ }^{-1}$, sendo estatisticamente superior à instalação em pós-plantio. Já em relação ao mulching branco, não foi observada diferença significativa para essa característica, entre as épocas de instalação.

A característica comprimento médio de frutos apresentou como resultado da análise de variância, efeito significativo de modo isolado, somente para o fator cor de mulching. Utilizando-se filmes plásticos prata e preto, com 3,41 e 3,08 $\mathrm{cm}$ fruto $^{-1}$, respectivamente, independentemente da época de instalação, os frutos apresentaram maior medida, sendo estatisticamente superiores ao filme plástico de cor branca, que promoveu um comprimento médio de $2,91 \mathrm{~cm}$ fruto $^{-1}$ (Tabela 2). O desenvolvimento da planta e do fruto está diretamente relacionado com a temperatura. Todas as culturas apresentam para cada fase fenológica, uma temperatura ótima que possibilita expressar o seu potencial. De acordo com Ronque (1998), temperatura entre 18 e $24^{\circ} \mathrm{C}$ favorece a frutificação do morangueiro. Assim, supõe-se que, em razão da época de colheita, provavelmente, mulching de coloração prata e preta proporcionaram uma temperatura de solo levemente superior, suficiente para promover maior desenvolvimento dos frutos quando comparado com o mulching branco, uma vez que, essa coloração, favorece a redução da temperatura.

Finalizada a colheita, calculou-se a soma da massa total de fruto e dividiu-se pelo número de plantas, obtendo-se a massa média de fruto por planta, onde foi verificado efeito significativo, de modo isolado para os fatores época de instalação e cor de mulching, assim como para a interação entre os mesmos. Os resultados foram semelhantes aos da característica número de frutos por planta. Desdobrando-se o fator cor de mulching dentro de cada época de instalação, para ambas as épocas, os filmes plásticos preto e prata foram estatisticamente superiores ao branco. Em pré-transplantio, a massa média de fruto por planta observada foi de 545,0 e 510,0 g planta $^{-1}$, respectivamente, para preto e prata, e de 390,0 g planta $^{-1}$ para o mulching branco. Já em pós-transplantio, os resultados obtidos foram de 490,0 ; 
485,0 e 371,0 g planta $^{-1}$, respectivamente para preto, prata e branco (Tabela 1). Os valores obtidos com o uso dos filmes plásticos preto e prata foram semelhantes aos observados por Oliveira \& Scivittaro (2009), que nas condições do Rio Grande do Sul, testando diferentes procedências e tempo de vernalização de mudas, obtiveram em mudas não vernalizadas, massa média de 491,7 g planta $^{-1}$. Quanto ao desdobramento de épocas de instalação dentro de cada cor de filme plástico, pode-se observar que com os filmes prata e preto, a massa média de frutos por planta foi maior, quando a instalação foi realizada em pré-transplantio, sendo estatísticamente superiores à instalação pós-transplantio. Já para o mulching branco, não foi observada diferença significativa entre as épocas de instalação. De modo semelhante, Kikas \& Luik (2011) em trabalho avaliando diferentes tipos de mulching na cultura do morangueiro, chegaram à conclusão de que o de cor preta possibilitou, entre outros benefícios, melhor rendimento produtivo.

Quanto ao número médio de folhas por planta, essa característica apresentou resultado significativo, apenas de modo isolado para cor de mulching (Tabela 2). Para esse fator, o maior número médio de folhas foi obtido com o uso do filme plástico de cor prata (10,33 folhas plan$\left.\operatorname{ta}^{-1}\right)$, sendo estatisticamente equivalente ao de cor preta $\left(9,83\right.$ folhas planta $\left.{ }^{-1}\right)$ e ambos superiores ao branco $(9,00$ folhas planta $\left.^{-1}\right)$. Para a cultura da alface, Zizas et al. (2002) verificaram uma resposta oposta, ou seja, quando compararam filmes plásticos de diferentes colorações em associação com diferentes cultivares, chegaram à conclusão de que o uso do filme branco proporcionou maior número de folhas, enquanto que o de cor preta a menor quantidade de folhas. Essa situação inversa, provavelmente, tenha ocorrido em função da época de cultivo, uma vez que o trabalho foi conduzido entre março e abril, período com temperaturas relativamente elevadas nas condições de Ilha Solteira (SP). Evidência reforçada pelo resultando apresentado pela cultivar Regina, material tolerante ao calor, que obteve a melhor resposta para esta característica. Assim, o uso de mulching branco proporcionaria menor absorção de calor e consequentemente, uma menor temperatura do solo, favorecendo o desenvolvimento da planta. Por outro lado, no caso do cultivo do morangueiro referente ao presente trabalho, sendo no período de inverno, o uso de mulching de coloração preta ou prata, ao contrário do branco, favoreceria a absorção de calor, e com isso, proporcionaria um aumento da temperatura do solo e, consequentemente, um maior desenvolvimento vegetativo da planta.

O comprimento de folíolo não foi afetado significativamente pelos tratamentos empregados nesse trabalho. Para essa característica, a média geral observada foi de 9,84 cm (Tabela 2).

Assim, diante dos resultados obtidos e nas condições em que foi conduzido o experimento, conclui-se que os filmes plásticos preto e prata promoveram aumento de rendimento e maior desenvolvimento de frutos, quando instalados em pré-transplantio das mudas de morangueiro.

\section{REFERÊNCIAS}

ALVARENGA JO. 2006. Classificação, embalagem e rotulagem do morango. In: CARVALHO SP (coord). Boletim de morango: cultivo convencional, segurança alimentar e cultivo orgânico. Belo Horizonte: FAEMG, 119-126.

COSTA FA; MEDEIROS JF; NEGREIROS MZ; BEZERRA NETO F; PORTO DRQ; CHAVES SWP; DANTAS KN. 2002. Rendimento de melão cantaloupe em diferentes coberturas de solo e lâminas de irrigação. Caatinga 15: 49-55.

EMBRAPA. 1999. Sistema brasileiro de classificação de solos. Centro Nacional de Pesquisa de Solos: Rio de Janeiro, 412p.

FERREIRA DF. 1999. SisVar: sistema de análise de variância para dados balanceados, versão 4.0. Lavras: DEX/UFLA. (Software estatística).

FILGUEIRA FAR. 2005. Novo Manual de Olericultura: agrotecnologia moderna na produção e comercialização de hortaliças. Viçosa: UFV. 402p.

GONÇALVES AO; FAGNANI MA; PEREZ JG. 2005. Efeitos da cobertura do solo com filme de polietileno azul no consumo de água da cultura da alface cultivada em estufa. Engenharia Agrícola 25: 622-631.

GROPPO GA; TESSARIOLI NETO J. 1991. A cultura do morangueiro. Campinas: CATI, 16p. (Boletim Técnico, 201).

KASPERBAUER MJ. 2000. Strawberry yield over red versus black plastic mulch. Crop Science 40: 171-174.

KIKAS A; LUIK A. 2011. The influence of different mulches on strawberry yield and beneficial entomofauna. Disponível em http:// www.actahort.org/books/567/567_154.htm. Acessado em 05 de abril de 2011.

LOCASCIO SJ; GILREATH JP; OLSON S; HUTCHINSON CM; CHASE CA. 2005. Red and black mulch color affects production of Florida strawberry. HortScience 40: 69-71.

NEGREIROS MZ; COSTA FA; MEDEIROS JF; LEITÃO VBRMM; BEZERRA NETO F; ESPÍNOLA SOBRINHO J. 2005. Rendimento e qualidade de melão sob lâminas de irrigação e cobertura de solo com filmes de polietileno de diferentes cores. Horticultura Brasileira 23: 773-779.

OLIVEIRA RP; SCIVITTARO WB. 2009. Produção de frutos de morango em função de diferentes períodos de vernalização das mudas. Horticultura Brasileira 27: 091-095.

RESENDE SR. 2001. Olericultura: a cultura do morango. Disponível em http://www.emater. mg.gov.br/site_emater/Serv_Prod/Livraria/ Olericul... Acessado em 05 de abril de 2011.

RIBEIRO AC; GUIMARÃES PTG; ALVAREZ VH. 1999. Recomendações para o uso de corretivos e fertilizantes em Minas Gerais. Viçosa: CFSEMG. 359 p. (5 a aproximação).

RONQUE ERV. 1998. Cultura do morangueiro: revisão e prática. Curitiba: EMATER. 206p.

SAMPAIO RA. 1999. Produção, qualidade dos frutos e teores de nutrientes no solo do tomateiro, em função da cobertura plástica do solo. Viçosa: UFV, 117p. (Tese doutorado).

SCICCO C. 2010. Morango deve ter novo aumento. Jornal Entreposto.com.br. Disponível em http://www.jornalentreposto.com.br/agricola/ hortifruti/1006-safra-de-morango-em-minasdeve-ter-novo-aumento. Acessado em 05 de abril de 2011.

SGANZERLA E. 1995. Nova Agricultura: a fascinante arte de cultivar com plásticos. 4ed. Porto Alegre: Plasticultura Gaúcha. 303p.

VEIGA JUNIOR WG de. 2006. O morango e sua evolução comercial. In: CARVALHO SP de (coord). Boletim de morango: cultivo convencional, segurança alimentar e cultivo orgânico. Belo Horizonte: FAEMG, 119-126.

ZIZAS GB; SENO S; FARIA JUNIOR MJA; SELEGUINI A. 2002. Interação de cultivares e cobertura do solo na produção e qualidade de alface (período de março a abril de 2001). In: CONGRESSO BRASILEIRO DE OLERICULTURA, 42, Resumos... Uberlândia: SOB (CD-ROM). 